\title{
TU/e EmonOWEN

\section{The existence of a biological equilibrium in a trickling filter for waste gas purification}

\section{Citation for published version (APA):}

Diks, R. M. M., Ottengraf, S. P. P., \& Vrijland, S. (1994). The existence of a biological equilibrium in a trickling filter for waste gas purification. Biotechnology and Bioengineering, 44(11), 1279-1287.

https://doi.org/10.1002/bit.260441103

DOI:

10.1002/bit.260441103

Document status and date:

Published: 01/01/1994

\section{Document Version:}

Publisher's PDF, also known as Version of Record (includes final page, issue and volume numbers)

\section{Please check the document version of this publication:}

- A submitted manuscript is the version of the article upon submission and before peer-review. There can be important differences between the submitted version and the official published version of record. People interested in the research are advised to contact the author for the final version of the publication, or visit the $\mathrm{DOI}$ to the publisher's website.

- The final author version and the galley proof are versions of the publication after peer review.

- The final published version features the final layout of the paper including the volume, issue and page numbers.

Link to publication

\section{General rights}

Copyright and moral rights for the publications made accessible in the public portal are retained by the authors and/or other copyright owners and it is a condition of accessing publications that users recognise and abide by the legal requirements associated with these rights.

- Users may download and print one copy of any publication from the public portal for the purpose of private study or research.

- You may not further distribute the material or use it for any profit-making activity or commercial gain

- You may freely distribute the URL identifying the publication in the public portal.

If the publication is distributed under the terms of Article 25fa of the Dutch Copyright Act, indicated by the "Taverne" license above, please follow below link for the End User Agreement:

www.tue.nl/taverne

Take down policy

If you believe that this document breaches copyright please contact us at:

openaccess@tue.nl

providing details and we will investigate your claim. 


\title{
The Existence of a Biological Equilibrium in a Trickling Filter for Waste Gas Purification
}

\author{
R. M. M. Diks, S. P. P. Ottengraf, * and S. Vrijland \\ Department of Chemical Process Engineering, Eindhoven University of \\ Technology, P.O. Box 513, 5600 MB Eindhoven, The Netherlands
}

Received January 3, 1994/Accepted July 26, 1994

Clogging is a well-known phenomenon in the application of a biological trickling filter for both waste gas and wastewater treatment. Nevertheless, no such observations or even significant changes in pressure drop have ever been recorded during the long-term processing of a waste gas containing dichloromethane (DCM) as a sole carbon source. To obtain more information about this phenomenon, a detailed investigation into the carbon balance of this system has been performed. During a period of operation of about 200 days the rate of DCM elimination and the overall rate of $\mathrm{CO}_{2}$ production in a continuously operating filter were therefore recorded daily, thus allowing an evaluation of the overall conversion process. Furthermore pseudo-steady-state measurements were carried out on a regular basis. These experiments reveal more detailed information on the actual DCM conversion by Hyphomicrobium GJ21 within the biofilm. The combined results of the experiments described in this article show that on an overall basis a so-called biological equilibrium, i.e., a situation of no net biomass accumulation, is obtained in the course of time. It appeared that the overall rate of $\mathrm{CO}_{2}$ production slowly increased until, after some $\mathbf{2 0 0}$ days, it finally counterbalanced the conversion rate of DCM on a molar basis. As opposed to this result, all pseudo-steady-state experiments indicated that about $60 \%$ of the eliminated primary carbon source is converted into biomass. This is in good agreement with results from microkinetic experiments. Based on these results and evaluation of the experimental data, it is concluded that interactions between several microbial populations are involved in this biological equilibrium. These interactions include both biomass growth and biomass degradation. (c) 1994 John Wiley \& Sons, Inc.

Key words: waste gas $\cdot$ trickling filter $\cdot$ biofilm $\cdot$ dichloromethane $\cdot$ biofiltration $\cdot$ air pollution

\section{INTRODUCTION}

Intensive research during the last 5 years has shown that the biological trickling filter (BTF) is well suited for the purification of waste gases. This bioreactor system is especially suited for the elimination of contaminants, the degradation of which results in the formation of acidifying products, e.g., the production of hydrochloric acid during the degradation of dichloromethane (DCM) ${ }^{6,7,10}$ Although these results are very promising, the practical application of trick-

* To whom all correspondence should be addressed. ling filter systems is also subjected to more requirements than a high degree of efficiency only. To compete with other waste gas purification systems, biological as well as conventional, the long-term operational stability and reliability of the system should be guaranteed. ${ }^{4}$

In a previous study ${ }^{6,7}$ it was shown that the biomass, which developed during the long-term operation of a trickling filter eliminating DCM as a sole carbon source, only partly consisted of Hyphomicrobium GJ21. This may be surprising as the number of germs able to grow on this xenobiotic compound is very limited. Questions arise as to the mechanism by which this phenomenon is brought about and what are the consequences for the operational stability. Operational stability is generally referred to as a constant substrate elimination rate in time at a sufficiently high level. Substrate degradation implies a continuous production and accumulation of biomass in the system. On one hand, this is very advantageous as biomass is continuously renewed. This may result in an adaptation of the biomass toward a higher activity. ${ }^{5}$ On the other hand, excessive biofilm development in the system will lead to an increased pressure drop and eventually to complete clogging of the filter bed. ${ }^{12,17}$

As far as available, literature data on laboratory-scale or pilot-plant trickling filters indeed show that clogging can occur. Depending on the experimental set-up and the physiological and process conditions applied, this process generally takes place within a period of several weeks. In the removal of $0.04-0.4 \mathrm{~g} / \mathrm{m}^{3}$ of propionaldehyde clogging was observed after 3 to 5 weeks in a $2-\mathrm{dm}^{3}$ BTF, applying 9-15 mm Raschig rings. ${ }^{9}$ The elimination of ethanol $\left(C_{g o}=3-8\right.$ $\mathrm{g} / \mathrm{m}^{3}$ ) appeared to result in an increased pressure drop and eventually blocking of the packed bed. ${ }^{11}$ Our own investigations to the removal of both 1,2-dichloroethane $\left(C_{g o}=\right.$ $\left.0.6-2.5 \mathrm{~g} / \mathrm{m}^{3}\right)$ and toluene $\left(C_{g o}=0.8-8 \mathrm{~g} / \mathrm{m}^{3}\right)$ gave rise to either process instabilities or clogging in a packed bed of $1 / 2$-in. Intalox saddles, within periods of typically 3 to 4 weeks. Clogging was also observed during the removal of a mixture of DCM and acetone $\left(C_{g o}\right.$ values of 1.6 and 0.7 $\mathrm{g} / \mathrm{m}^{3}$, respectively) in a BTF, using a structured PVC packing material. ${ }^{5}$ Within a period of 7 weeks an increase of the pressure drop from only 20-30 $\mathrm{Pa}$ up to $2 \times 10^{4} \mathrm{~Pa}$ at a superficial gas flow rate of $200 \mathrm{~m} / \mathrm{h}$ was recorded, whereas 
the packing material appeared to be almost completely blocked.

As opposed to these negative results, short-term as well as long-term experiments have shown that a high elimination efficiency and operational stability can be obtained for the elimination of DCM in a BTF, even during periods of several years. Moreover, at the loading conditions applied (i.e., inlet gas concentrations of $0.5<C_{g o}<2.5 \mathrm{~g} / \mathrm{m}^{3}$ at $\mathrm{v}_{g}$ $=200 \mathrm{~m} / \mathrm{h}$ ) the process was characterized by a very low and constant pressure drop. For example, the pressure drop over a $2.7-\mathrm{m}$ filter bed consisting of a crossflow type of packing material (C10-12 PVC, ME, Germany) never exceeded $10-30 \mathrm{~Pa}^{5}$

Although one would expect otherwise, based on microkinetic observations, this successful long-term DCM elimination and the absence of clogging seems to indicate that the net accumulation of the DCM-degrading biomass in this particular case is rather low. In contradiction with a biomass yield on DCM of $0.6 \mathrm{~mol} \mathrm{C}_{\text {biomass }} / \mathrm{mol} \mathrm{C}_{\mathrm{DCM}}$, the net production of biomass in the system appeared to level off in the long run. Nevertheless, the external removal of biomass from the system was negligible.

To obtain more information on the actual process of biomass accumulation and on the most important carbonconverting processes, a closer investigation of the carbon balance in a DCM-eliminating trickling filter was carried out. Especially the development of the biological activity in the system, as described by a number of characteristic parameters, was therefore recorded as a function of time during a long period of operation.

\section{REACTOR SYSTEM AND EXPERIMENTAL SET-UP}

\section{Biological Trickling Filter}

The laboratory-scale BTF applied during these experiments consisted of a glass column (diameter $0.3 \mathrm{~m}$, height $1.5 \mathrm{~m}$, Quick-fit, UK) filled to a height of $1 \mathrm{~m}$ with 1 -in. Super Torus saddles (Raschig, Germany). The column (Fig. 1) was completely protected from daylight in order to prevent the development and growth of algae. A synthetic waste gas, which was introduced at the bottom of the column $\left(\mathrm{v}_{g}\right.$ $=200 \mathrm{~m}^{3} / \mathrm{m}^{2} \cdot \mathrm{h}$ ), was created by continuously injecting liquid DCM into an airflow. The storage vessel of DCM was connected to a capillary with a length of $6 \mathrm{~m}$ and an inner diameter of $0.3 \mathrm{~mm}$. By pressurizing the storage vessel a known and constant flow of DCM was produced. The injection took place in a flange with a central opening of 10 $\mathrm{mm}$. Due to the high local gas velocity, immediate evaporation of the DCM took place. In this way concentrations ranging from $100 \mathrm{mg} / \mathrm{m}^{3}$ to $10,000 \mathrm{mg} / \mathrm{m}^{3}$ could be produced.

The water phase was continuously recirculated and sprayed over the bed, on top of a Veiki distribution system (Polarcel, The Netherlands). This distribution system consists of three polyethylene decks, which are formed of a

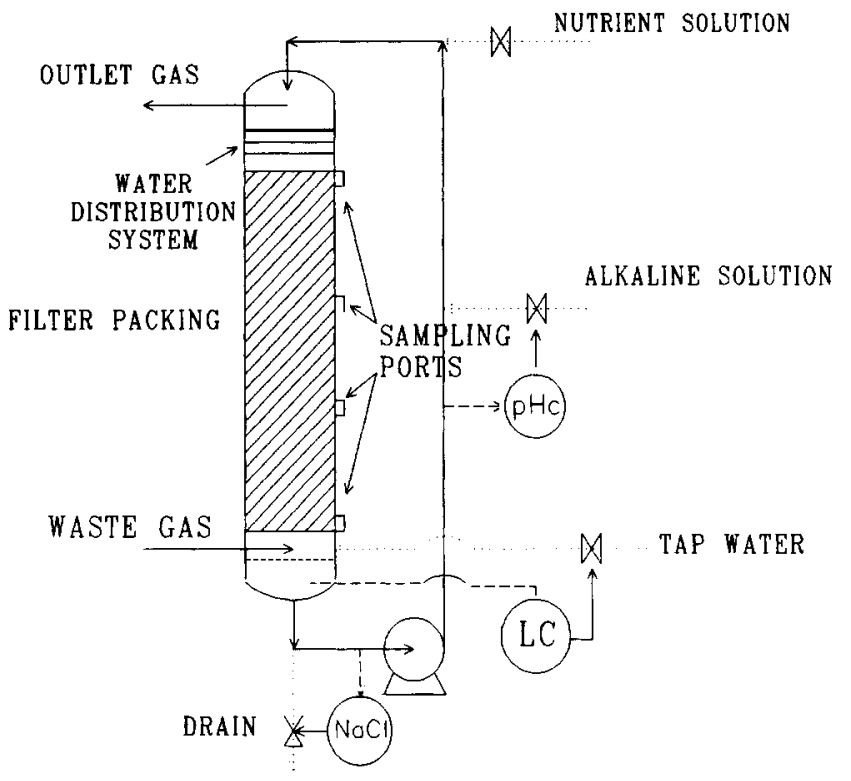

Figure 1. Experimental set-up of a biological trickling filter system. The packing material consists of a 1 -in. PP-Super Torus saddles.

rectangular network of slats (the distance between the slats is $40 \mathrm{~mm}$, the height of a slat is $18 \mathrm{~mm}$ ). To provide a uniform distribution of water over the deck, each individual slat is grooved on top. Important advantages of this distributor are its negligible pressure drop and the absence of obstructions that are responsible for blocking by the biomass present in the water phase (as occurs with nozzles). The superficial water velocity was set at $6.2 \mathrm{~m}^{3} /\left(\mathrm{m}^{2} \cdot \mathrm{h}\right)$. The liquid from the filter bed was collected at the bottom, where the $\mathrm{pH}$ of the liquid phase (7.8) was controlled (Radiometer, Denmark) by dosing an alkaline solution ( $5 \mathrm{M}$ $\mathrm{NaOH}$, Merck, USA) to neutralize the hydrochloric acid which is formed during the biological DCM degradation. On a daily basis the average flow rate of the alkaline solution was determined by recording the content of the storage vessel (inaccuracy less than 5\%).

The liquid phase, with a temperature of $19-21^{\circ} \mathrm{C}$, was continuously recirculated to the top of the column. As a high concentration of neutralization products (viz. $\mathrm{NaCl}$ ) inhibits the biological activity, a continuous drain of liquid from the reactor took place via an overflow. At the same time fresh medium was pumped to the reactor by a plunger pump (DCL, UK), to compensate for both the water evaporated and the effluent. Based on the liquid outflow and $\mathrm{NaCl}$ concentration (determined by conductivity), the influent flow (generally about $0.3 \mathrm{dm}^{3} / \mathrm{h}$ ) was corrected daily, resulting in a constant volume of the liquid phase and a $\mathrm{NaCl}$ concentration of $300 \mathrm{mM}$.

\section{Materials and Methods}

\section{Bacteria}

The reactor described above was inoculated with a biomass suspension, which will be referred to as trickling filter en- 
richment culture, taken from another laboratory trickling filter eliminating DCM. The DCM-degrading strain $H y$ phomicrobium sp. GJ $21^{11,13}$ has initially been used as an inoculum to this reactor system. During the biological degradation of DCM $2 \mathrm{~mol}$ of $\mathrm{HCl}$ is produced per mol of DCM eliminated. $^{5}$

\section{Medium}

The inorganic medium was based on tap water to which phosphate, ammonium, and iron were added. The total ammonium requirement of the biomass in the system was estimated from a general biomass composition formula $\mathrm{C}_{5} \mathrm{H}_{7} \mathrm{NO}_{2} \mathrm{P}_{1 / 30}$, a yield coefficient of $0.6 \mathrm{~mol} \mathrm{C}_{\text {biomass }} / \mathrm{mol}$ $\mathrm{C}_{\mathrm{DCM}}$ and an average degree of conversion for ammonium, arbitrarily set at $50 \%$. As the production rate of $\mathrm{NaCl}$ and the consumption rate of ammonium are coupled, it can be shown that according to the corresponding mass balances, the $\left(\mathrm{NH}_{4}\right)_{2} \mathrm{SO}_{4}$ concentration in the influent flow to the reactor should thus amount to $3 \mathrm{~g} / \mathrm{dm}^{3}$ if a NaCl concentration of $300 \mathrm{~m} M$ is to be maintained. Furthermore, 0.25 $\mathrm{g} / \mathrm{dm}^{3} \mathrm{KH}_{2} \mathrm{PO}_{4}$ and $0.001 \mathrm{~g} / \mathrm{dm}^{3} \mathrm{FeSO}_{4} \cdot 7 \mathrm{H}_{2} \mathrm{O}$ were added.

\section{Gas Phase Analysis}

Dichloromethane concentrations were determined with a Carlo Erba 4300 gas chromatograph provided with a flame ionization detector resulting in an inaccuracy less than $1 \%$. A Chromosorb 101 column of $3 \mathrm{~m}$ was used at $130^{\circ} \mathrm{C}$, whereas nitrogen was the carrier gas.

Carbon dioxide concentrations were analyzed on a Carlo Erba HWD 4300 gas chromatograph provided with a dual thermal conductivity detector and a 2-m Porapac $\mathrm{Q}$ column (Porapac, NL) at $35^{\circ} \mathrm{C}$. Helium (purity 5.0, Hoekloos, NL) was used as carrier gas at a flow rate of $25 \times 10^{-3} \mathrm{dm}^{3} /$ min. Two-hundred-fifty-microliter gas samples, taken in the inlet and outlet gas flows, were directly injected in the gas chromatograph with gas-tight syringes. Calibration of these measurements was performed, using calibration mixtures in the range of 100 to $1000 \mathrm{ppm} \mathrm{CO}_{2}$. These mixtures were prepared by injecting known amounts of $\mathrm{CO}_{2}$ (5.0, Air Products, NL) into closed bottles of exactly known volume filled with helium, with gas-tight syringes (Hamilton, UK). All measurements were carried out in triplicate. The resulting inaccuracy of the $\mathrm{CO}_{2}$ analysis was generally about $2 \%$.

\section{Liquid Phase Analysis}

Inorganic carbon concentration in the liquid phase was determined indirectly. A $0.1-\mathrm{dm}^{3}$ liquid sample was acidified $(\mathrm{pH} \leqslant 1)$ in a $0.25-\mathrm{dm}^{3}$ flask using a few drops of concentrated hydrochloric acid, after which it was shaken vigorously. Through a rubber septum a $250-\mu \mathrm{L}$ gas sample was taken and analyzed as described above. From the analysis result thus obtained, the gas and liquid volumes and the gas-liquid distribution coefficient $\left(m=1.05\right.$ at $\left.20^{\circ} \mathrm{C}^{14}\right)$ the total liquid phase carbonate concentration was calculated (inaccuracy 5-10\%).

The total organic carbon concentration in the liquid phase was determined on a total organic carbon (TOC) analyzer (Dohrmann Envirotech), which was calibrated through glucose solutions of exactly known concentrations in the range of $0-0.5 \mathrm{~g} \mathrm{C} / \mathrm{dm}^{3}$. After acidification to $\mathrm{pH} \leqslant 1$ in a liquidfilled flask, a $30-\mu \mathrm{L}$ sample was injected in the TOC.

\section{RESULTS}

After start-up of the system the elimination of DCM was followed during a total period of about 200 days. Initially, the influent DCM concentration was maintained at 0.20 $\mathrm{g} / \mathrm{m}^{3}$. However, as the carbon dioxide production appeared to be rather low at these conditions, the inlet concentration was increased to $0.80 \mathrm{~g} / \mathrm{m}^{3}\left(9.4 \times 10^{-3} \mathrm{~mol} / \mathrm{m}^{3}\right)$ after 60 days. The complete set of process conditions thus maintained during the remainder period of operation will further be referred to as standard conditions.

The removal performance or elimination capacity (EC) of the trickling filter is expressed as mass of substrate converted per unit of reactor volume and time, $\mathrm{mol} \mathrm{C} /\left(\mathrm{m}^{3} \cdot h\right)$. As this magnitude is independent of the reactor volume applied, it can be considered as a characteristic parameter, which allows a direct comparison to the performance of other reactor systems or experimental set-ups. During the experiments, this elimination capacity was determined daily from the amount of alkaline solution consumed (inaccuracy $2 \%$ ) as well as from the decrease of the gas phase DCM concentration $\left[\mathrm{EC}_{\mathrm{GLC}}=\mathrm{v}_{g} \cdot\left(C_{g o}-C_{g e}\right) / \mathrm{H}\right]$. Correspondingly the elimination rates thus recorded are referred to as the standard ECs.

In Figure 2 the organic load, calculated according to $\mathrm{v}_{g} \cdot C_{g o} / H$, as well as the standard elimination capacity based on $\mathrm{NaOH}$ consumption and gas-liquid chromatography (GLC) analysis are plotted vs. time. This figure shows that within a period of 2 weeks after start-up a rather steadystate elimination capacity of $0.25 \mathrm{~mol} \mathrm{C} /\left(\mathrm{m}^{3} \cdot \mathrm{h}\right)$ was obtained. After increasing the inlet gas concentration $C_{g o}$ to

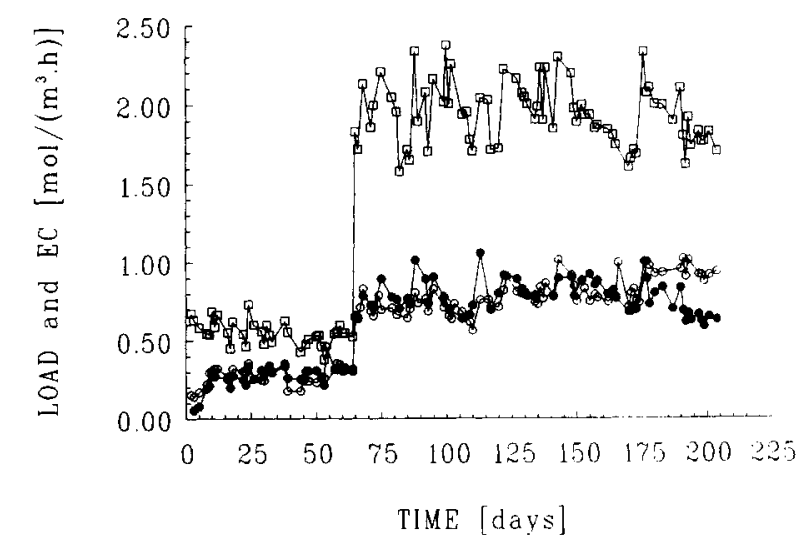

Figure 2. The molar organic load and elimination capacity at standard conditions vs. time: load ( $\square$ ); $\mathrm{EC}_{\mathrm{NaOH}}(\mathrm{O}) ; \mathrm{EC}_{\mathrm{GLC}}(\mathbf{O})$. 
$0.8 \mathrm{~g} / \mathrm{m}^{3}$, the EC immediately increased to $0.75 \mathrm{~mol} /$ $\left(\mathrm{m}^{3} \cdot \mathrm{h}\right)$, which corresponds to a removal efficiency of $40 \%$. The variation observed in the elimination capacities most likely results from instabilities in the organic load (Fig. 2).

Although the removal of DCM from the gas phase does not necessarily imply biological degradation, it can be seen from Figure 2 that the $\mathrm{EC}_{\mathrm{NaOH}}$ and $\mathrm{EC}_{\mathrm{GLC}}$, which are determined independently of each other, are generally comparable. It should be noted that the removal of DCM via the liquid drain is negligible as compared to removal by biological elimination. From the maximum equilibrium concentration in the liquid phase $\left(C_{g o} / m=9.4 \times 10^{-2} \mathrm{~mol} /\right.$ $\mathrm{m}^{3}$ ) and the effluent flow rate of $3 \times 10^{-4} \mathrm{~m}^{3} / \mathrm{h}$, a maximum DCM removal by the drain of $3 \times 10^{-5} \mathrm{~mol} /\left(\mathrm{m}^{3} \cdot \mathrm{h}\right)$ is estimated. Furthermore, the consumption of $\mathrm{NaOH}$ becomes negligible once the inlet gas concentration of DCM is reduced to zero and hence the $\mathrm{EC}_{\mathrm{NaOH}}$ and $\mathrm{EC}_{\mathrm{GLC}}$ both reflect the removal by biological elimination.

From day 60 on also the rate of $\mathrm{CO}_{2}$ production in the gas phase was determined on a regular basis. From the inlet and outlet $\mathrm{CO}_{2}$ concentrations in the waste gas the gas phase related production rate of carbon dioxide at standard conditions $\left(R_{\mathrm{CO}_{2}-\mathrm{st}}\right)$ was calculated, which is plotted vs. time in Figure 3. Despite the presence of considerable fluctuations a gradual increase of the $\mathrm{CO}_{2}$ production rate with time can be observed.

Fluctuations in $R_{\mathrm{CO}_{2} \text {-st }}$ may probably be caused by fluctuations of the organic load and/or the fairly low accuracy of the $\mathrm{CO}_{2}$ analysis procedure. The latter is due to the small increase of the gas phase $\mathrm{CO}_{2}$ concentration as compared to the standard error of the $\mathrm{CO}_{2}$ analysis. To avoid this effect and to increase the reliability of the results, experiments were also performed with $\mathrm{CO}_{2}$-free waste gas. For this purpose a $0.45 \times 0.1-\mathrm{m}$ adsorption column filled with sodium lime granules ( $1 \mathrm{~mm}$, Merck, Germany) was installed in the system at day 140 . As shown in the break-through curves in Figure 4, this resulted in a reduction of the $\mathrm{CO}_{2}$ inlet concentration below $3 \mathrm{ppm}$ (detection limit) during at least $3 \mathrm{~h}$ of operation and hence a significant increase of the data

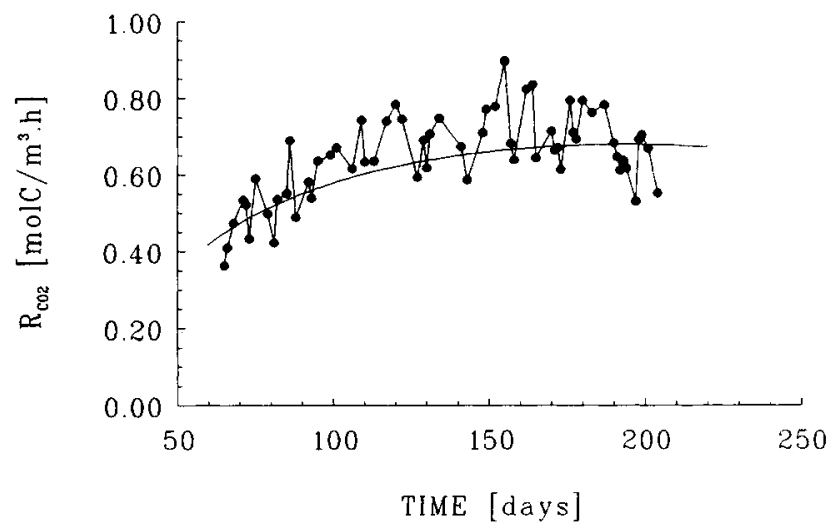

Figure 3. The gas phase related $\mathrm{CO}_{2}$ production rate in the BTF vs. time at standard conditions: $v_{g}=200 \mathrm{~m} / \mathrm{h} ; v_{l}=6.2 \mathrm{~m} / \mathrm{h} ; C_{g \circ}=0.8 \mathrm{~g} / \mathrm{m}^{3}$.

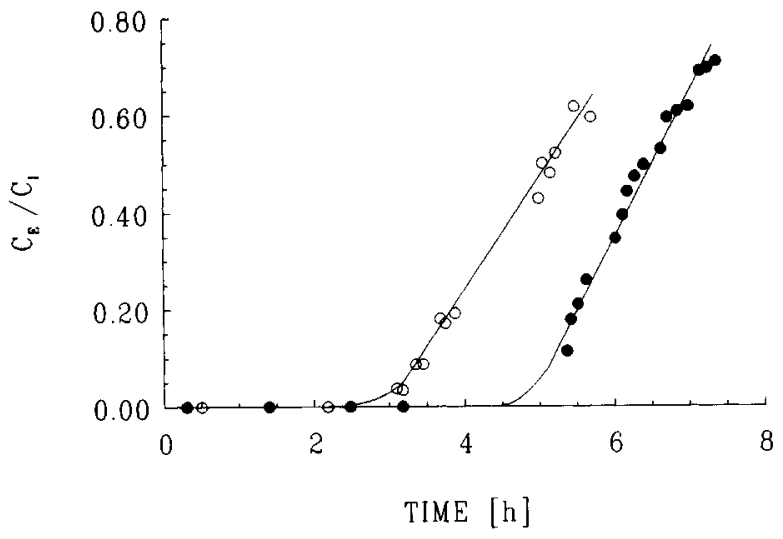

Figure 4. The relative $\mathrm{CO}_{2}$ concentration in the inlet gas phase applying a sodium lime adsorption column. Height: $0.4 \mathrm{~m}(\mathrm{O})$ and $0.6(\mathrm{O})$ (detection limit 3 ppm).

accuracy. Nevertheless, this provision did not result in a reduction of the $R_{\mathrm{CO}_{2}}$ fluctuations, as shown in Figure 3 . Apparently this phenomenon is mainly due to the fluctuating organic load.

Apart from the daily elimination capacity at standard conditions, the DCM elimination capacity and $\mathrm{CO}_{2}$ production rate were also determined regularly at increasing inlet DCM concentrations in the range of 0.2 to $10 \mathrm{~g} / \mathrm{m}^{3}$. It is very important to note that this type of experiment is carried out in less than 1 day, in order not to induce significant changes in the biomass activity or its concentration. It can thus be regarded as a pseudo-steady-state experiment. At each inlet gas concentration the $\mathrm{EC}_{\mathrm{GLC}}$ was calculated from the degree of conversion in the gas phase. However, for a gas phase degree of conversion lower than $10 \%$, i.e., at high inlet concentrations, the consumption of hydroxide solution was recorded as well in order to calculate $\mathrm{EC}_{\mathrm{NaOH}}$, due to the relatively low GLC accuracy. The resulting performance curve can be considered as a characteristic feature of the momentary biological activity of the system ${ }^{6,7}$ and was hence recorded about every 2 weeks.

In preliminary tests the response of the outlet $\mathrm{CO}_{2}$ concentration to an increase in the inlet DCM concentration was recorded to investigate the rate of accumulation of $\mathrm{CO}_{2}$ in the liquid phase (especially carbonates). The results indicate that for the typical stepwise increases of the inlet concentration applied, a pseudo-steady-state situation was obtained in about $20 \mathrm{~min}$ (Fig. 5), whereas for DCM this process was even faster. In all experiments involving the performance curve the conversion and production rates were therefore determined at least $30 \mathrm{~min}$ after the increase of the inlet DCM concentration. From day 140 on $\mathrm{CO}_{2}$-free gas was applied here as well.

In Figure 6 an example of a performance curve is shown, as was determined at day 207. It shows that an increased elimination capacity results in a higher $\mathrm{CO}_{2}$ production rate. Furthermore, it should be noted that even without the addition of DCM a fairly high rate of $\mathrm{CO}_{2}$ production is observed.

The complete set of the DCM performance curves, re- 


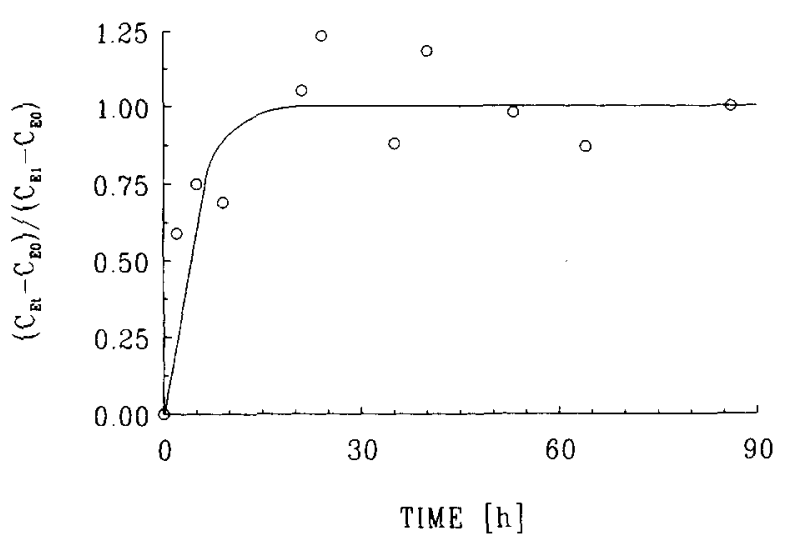

Figure 5. The response of the outlet $\mathrm{CO}_{2}$ concentration upon a stepwise increase of the inlet DCM concentration as applied in the determination of a performance curve.

corded during the total period of operation, is shown in the Figures 7 and 8. From these graphs it can be observed that the $\mathrm{EC}_{\max }$ continuously increases during the first 3 months. Moreover, Figure 8 shows that the maximum elimination capacity finally levels off to a constant value of about 3.2 $\mathrm{mol} /\left(\mathrm{m}^{3} \cdot \mathrm{h}\right)$ between days 87 and 116 .

\section{DISCUSSION}

Comparing the paths of the $\mathrm{EC}$ and $\mathrm{EC}_{\max }$ in the course of time (Figs. 2, 7, and 8) it can be concluded that biofilm growth still continues (Figs. 7 and 8 ), despite a constant standard EC being reached (Fig. 2). Speaking in terms of biofilm models, ${ }^{15,18}$ this can be explained as follows. Starting with a very thin reaction-limited biofilm, after some 15 days a diffusion-limited state is apparently obtained due to growth. Although from this moment on the standard elimination capacity remains unchanged, microbial growth and hence an increase of the biofilm thickness continues. This development is illustrated by the increase of the $\mathrm{EC}_{\max }$ and $\mathrm{R}_{\mathrm{CO}_{2} \text {-st }}$, which continues until about day 110 . Due to an increasing mass transfer resistance and rate of consumption,

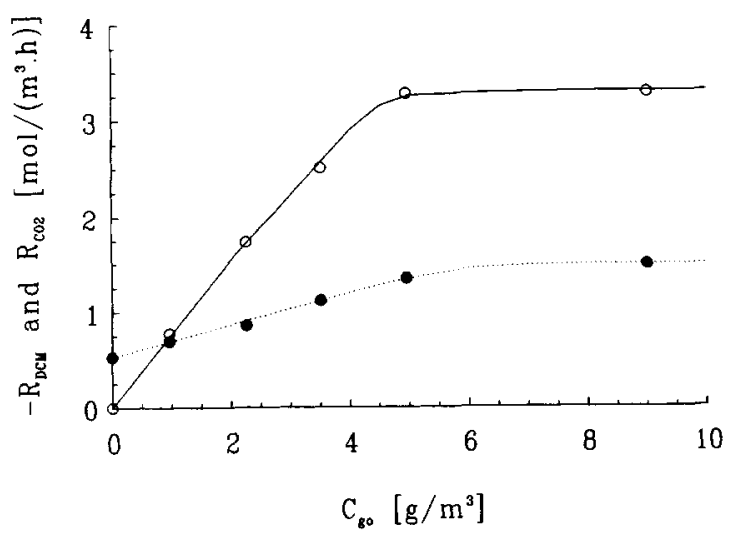

Figure 6. The DCM elimination $(O)$ and simultaneous production of $\mathrm{CO}_{2}(\mathrm{O})$ in the BTF vs. the inlet DCM concentration (performance curve) as determined at day 207 .

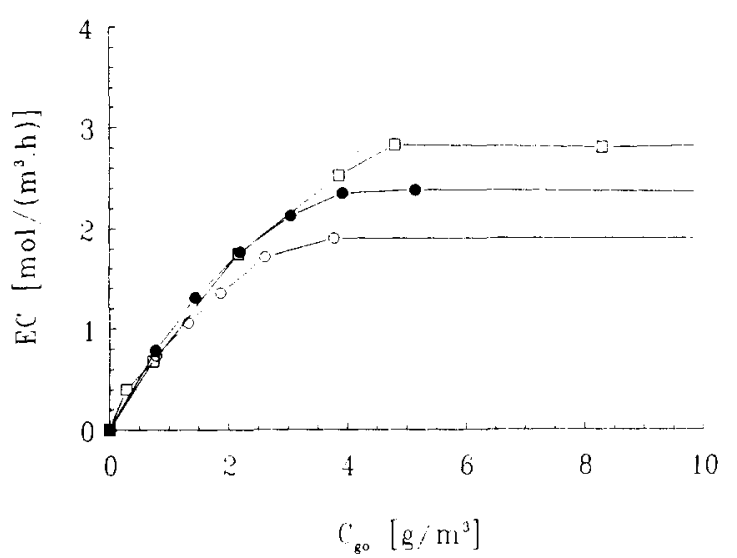

Figure 7. Experimentally determined performance curves at days 67 (O), $74(\bigcirc), 87(\square)$.

the supply of oxygen to deeper parts of the biofilm becomes limited, ${ }^{2,3}$ and hence the $\mathrm{EC}_{\max }$ will finally level off as well (Fig. 8).

Comparing this result with the data given in Figure 3, it can be observed that a constant $R_{\mathrm{CO}_{2} \text {-st }}$ around day 110 is obtained as well. This is quite surprising as the DCM elimination at standard conditions was already constant for a considerably longer period of time (Fig. 2). Apparently biological changes, not directly related to the DCM elimination, have continued during this period. Consequently this implies that the $\mathrm{CO}_{2}$ production rate at standard conditions, as given in Figure 3, cannot be entirely due to the elimination of DCM only.

An investigation of the carbon balance in more detail is thus required. This involves the $\mathrm{CO}_{2}$ fluxes via both the gas and the liquid flows through the system. Although the drain of liquid from the BTF is rather small $\left(3 \times 10^{-4} \mathrm{~m}^{3} / \mathrm{h}\right)$, especially the total amount of dissolved carbonates at the $\mathrm{pH}$ of 7.8 and the concentration of suspended organic matter (biomass) might be important with respect to the total rate of carbon removal from the system.

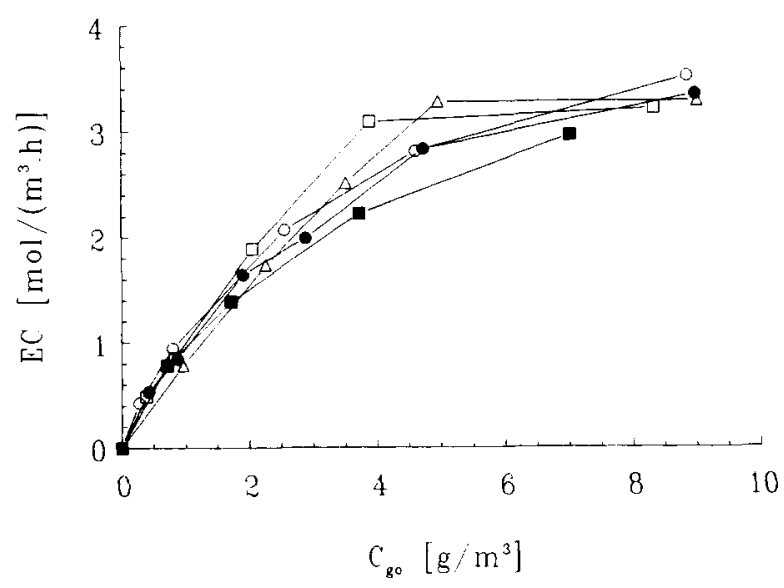

Figure 8. Experimentally determined performance curves at days 116 (O), $123(\bigcirc), 150(\square), 165(\mathbb{C}), 207(\triangle)$. 
The total organic carbon and inorganic carbonate contents of the liquid phase were therefore determined as described earlier. The resulting experimental data were thereafter recalculated for each carbon flux as a volumetric production rate of $\mathrm{CO}_{2}$ in the BTF. In Figure 9 these data are plotted vs. time, as the percentage of each carbon flow relative to the total amount of $\mathrm{DCM}$ converted $\left(\mathrm{EC}_{\mathrm{GLC}}\right)$. The latter quantity was taken from Figure 2, as the flux of DCM removed via the drain is negligible, as shown earlier.

From Figure 9 it can easily be concluded, that a major part of the carbon dioxide produced is removed via the gas phase, which is mainly due to the high volumetric gas flow applied. Only 3-4\% of the carbon converted in the trickling filter is removed as suspended and solved organic material with the liquid drain (average $R_{\text {org }}=3 \times 10^{-2} \mathrm{~mol}$ $\mathrm{C} /\left(\mathrm{m}^{3} \cdot \mathrm{h}\right)$ ). The removal rate of inorganic carbon via the drain was even lower (average $R_{\text {inorg }}=3 \times 10^{-3} \mathrm{~mol}$ $\left.\mathrm{C} /\left(\mathrm{m}^{3} \cdot \mathrm{h}\right)\right)$.

In Figure 3 it was shown that after start-up the overall production rate of $\mathrm{CO}_{2}$ gradually increased until it leveled off at a value of about $0.7 \mathrm{~mol} \mathrm{C} /\left(\mathrm{m}^{3} \cdot \mathrm{h}\right)$. Comparing this result to the molar DCM elimination rate at standard conditions of $0.75 \mathrm{~mol} \mathrm{C} /\left(\mathrm{m}^{3} \cdot \mathrm{h}\right)$, (Fig. 2), it appears that the $R_{\mathrm{CO}_{2}}$ finally approaches the $-R_{\mathrm{DCM}}$. As shown in Figure 9, this implies that the apparent overall $\mathrm{CO}_{2}$-yield coefficient of the trickling filter process becomes very close to 1 . This is not only an extremely high value in itself, it is also in contradiction to the results from microkinetic experiments mentioned above. This again indicates that, apart from the DCM-degrading process, a secondary biological process is taking place in the filter system which results in the production of carbon dioxide as well.

To quantify the contribution of both processes to the overall $\mathrm{CO}_{2}$ production rate, the data obtained in the performance-curve experiments were evaluated in another way. For each data set, the $R_{\mathrm{CO}_{2}}$ was plotted versus the $-R_{\mathrm{DCM}}$, as shown in Figure 10 for the performance curve recorded at day 150 . In this figure a striking direct proportionality can be observed between both quantities. It is very important to recall that the performance curves for the DCM

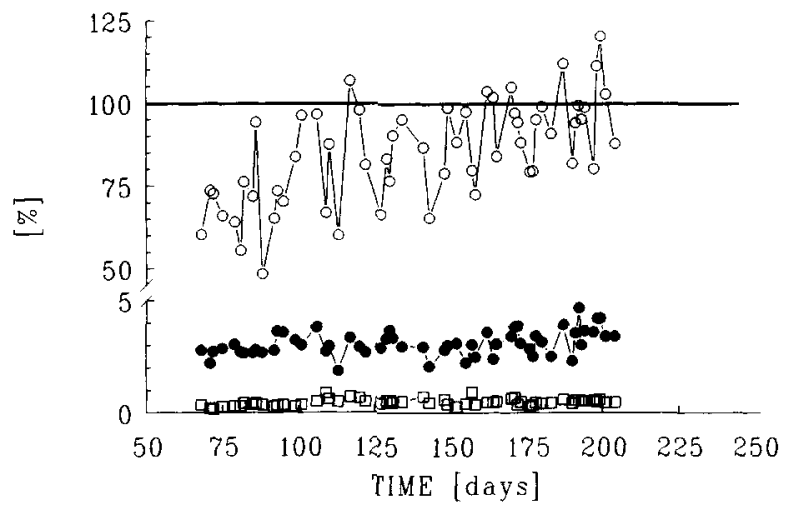

Figure 9. The production rates of $\mathrm{CO}_{2}$ in the gas phase $(\mathrm{O}), \mathrm{CO}_{2}$ in the drain $(\square)$, and organic $\mathrm{C}$ in the drain $(\mathbf{O})$ relative to the molar elimination capacity of DCM vs. time at standard conditions. elimination can be regarded as pseudo-steady-state experiments with respect to the biofilm characteristics, i.e., no biological changes are expected to occur. Consequently the $-R_{\mathrm{DCM}}$ and $R_{\mathrm{CO}_{2}}$ data in Figure 10 can only reflect the result of the primary reaction, i.e., the degradation of DCM. The ratio of both quantities thus reflects the $\mathrm{CO}_{2}$ yield coefficient of this DCM degradation process only. From Figure 10 a value of $0.36 \mathrm{~mol} \mathrm{C} \mathrm{Co}_{2} / \mathrm{mol} \mathrm{C}_{\mathrm{DCM}}$ is estimated and hence $Y_{s / x}=0.64$ mol C $\mathrm{C}_{\text {biomass }} / \mathrm{mol} \mathrm{C} \mathrm{C}_{\mathrm{DCM}}$. The linear relation observed in Figure 10 also suggests that these values for the yield coefficient are valid throughout the biofilm. As each increase of the inlet gas concentration results in an increased penetration depth of the DCM into the biofilm, the increase of the $-R_{\mathrm{DCM}}$ in Figures 6 and 10 is due to the increase of biomass involved in the elimination of DCM. Apparently this additional biomass, in deeper parts of the biofilm, is characterized by a similar behavior as compared to biomass at the surface of the biofilm. Using all performance data obtained (Figs. 7 and 8), plots similar to Figure 10 were constructed. In each of these plots a similar, linear correlation was obtained. By statistical analyses of the data, using the SAS package (SAS Institute Inc., Cary, USA) on a PC, the slope and vertical intercept of the best fitting straight lines were obtained (Table I). In Figure 11 the resulting values of $Y_{s / x}$ are plotted vs. time. The vertical bars in this figure indicate the $95 \%$ confidence interval as obtained from the regression procedure.

From Figure 11 can be observed that the yield coefficient on DCM is approximately constant during the whole period of operation. The data thus obtained are in good agreement with the results from batch kinetic experiments, which indicate that the $Y_{s / x}$ for both the Hyphomicrobium sp. GJ21 and the trickling filter enrichment culture amount to $0.6 \mathrm{~mol}$ $\mathrm{C}_{\text {biomass }} / \mathrm{mol} \mathrm{C}_{\mathrm{DCM}}$. $^{5}$

Except from the slope of the linear correlation, the vertical intercept in Figure 10 is an important parameter as well. It reflects the $\mathrm{CO}_{2}$ production due to processes other than DCM degradation. Most likely biomass degradation processes are involved here, which not only includes endogenous respiration but also involves the respiration of

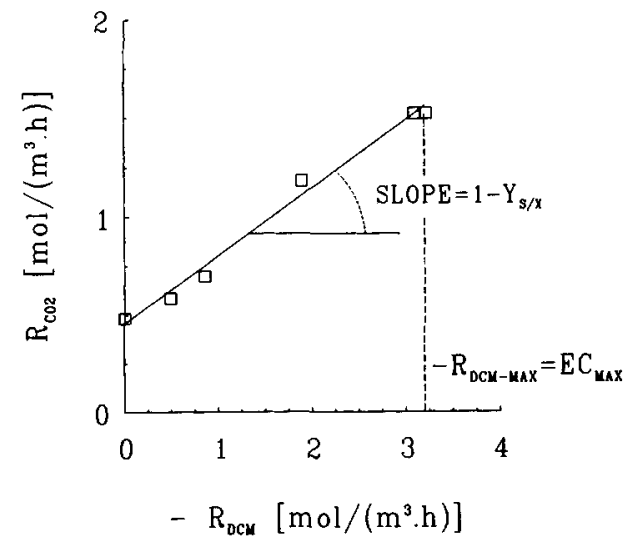

Figure 10. The molar production rate of carbon dioxide vs. the molar elimination rate of DCM as determined at day 150; best fit (solid line). 
Table I. The resulting biological parameters as calculated from the performance curves.

\begin{tabular}{|c|c|c|c|c|c|c|}
\hline $\begin{array}{l}\text { Time } \\
\text { (days) }\end{array}$ & $\begin{array}{c}Y_{\mathrm{s} / \mathrm{x}} \\
(\mathrm{mol} \mathrm{C} / \mathrm{mol} \mathrm{C})\end{array}$ & $c v^{b}$ & $\begin{array}{c}R_{\mathrm{ER}} \\
\left(\mathrm{mol} \mathrm{C} /\left(\mathrm{m}^{3} \cdot \mathrm{h}\right)\right]\end{array}$ & $\mathrm{cv}^{\mathrm{b}}$ & $\begin{array}{c}R_{\mathrm{CO}_{2-s t}{ }^{c}} \\
\left(\mathrm{~mol} \mathrm{C} /\left(\mathrm{m}^{3} \cdot h\right)\right]\end{array}$ & $\begin{array}{c}-R_{\mathrm{DCM}-\mathrm{st}}^{\mathrm{d}} \\
\left(\mathrm{mol} \mathrm{C} /\left(\mathrm{m}^{3} \cdot \mathrm{h}\right)\right]\end{array}$ \\
\hline 67 & 0.66 & 9 & 0.18 & 17 & 0.34 & 0.72 \\
\hline 74 & 0.59 & 12 & 0.20 & 35 & 0.48 & 0.84 \\
\hline 87 & 0.54 & 8 & 0.19 & 47 & 0.40 & 0.88 \\
\hline 89 & 0.51 & 18 & 0.35 & 40 & 0.68 & 0.74 \\
\hline 103 & 0.52 & 14 & 0.24 & 25 & 0.55 & 0.66 \\
\hline 116 & 0.60 & 9 & 0.27 & 15 & 0.52 & 0.71 \\
\hline 123 & 0.64 & 3 & 0.48 & 4 & 0.65 & 0.72 \\
\hline 150 & 0.64 & 6 & 0.44 & 14 & 0.64 & 0.77 \\
\hline 165 & 0.63 & 8 & 0.45 & 18 & 0.75 & 0.77 \\
\hline 207 & 0.73 & 11 & 0.48 & 17 & 0.70 & 0.64 \\
\hline
\end{tabular}

${ }^{a}$ Actual yield coefficient of DCM degradation $Y_{s / x}$, rate of endogenous respiration $R_{\mathrm{ER}}$ without DCM suppletion, and standard $\mathrm{CO}_{2}$ production rate $R_{\mathrm{CO}_{2}-\mathrm{st}}$.

Percent coefficient of variation (standard deviation $/$ mean) $\times 100 \%$.

'Data obtained from performance curves (e.g., Fig. 6).

${ }^{d}$ Elimination capacity $\left(\mathrm{EC}_{\mathrm{GLC}}\right)$ at standard conditions, as obtained from Fig. 2.

biogenic material in the biofilm (lysed cells) by secondary microbial populations. ${ }^{16}$ These populations may consist of higher organisms which prey upon the biomass, ${ }^{5}$ or secondary, non-DCM-utilizing microorganisms. ${ }^{8}$

Consequently the whole of these processes, which will nevertheless be referred to as endogenous respiration, can account for the additional $\mathrm{CO}_{2}$ production rate, required to explain the difference between the apparent and actual yield coefficient of the microbial flora on DCM (Figs. 9 and 11).

The high apparent yield coefficient for $\mathrm{CO}_{2}$ thus seems to be the result of a sequence of biological processes schematically drawn in Figure 12 . Overall these processes result in the development of a biological equilibrium, i.e., a situation of no net biomass production. This is in good agreement with the absence of any clogging phenomena due to excessive growth of biomass or an increase of the pressure drop over the system.

From the data in Table I it can be observed that the rate of endogenous respiration $R_{\mathrm{ER}}$ increases during the whole period of operation. Figure 13 graphically shows that $R_{\mathrm{ER}}$

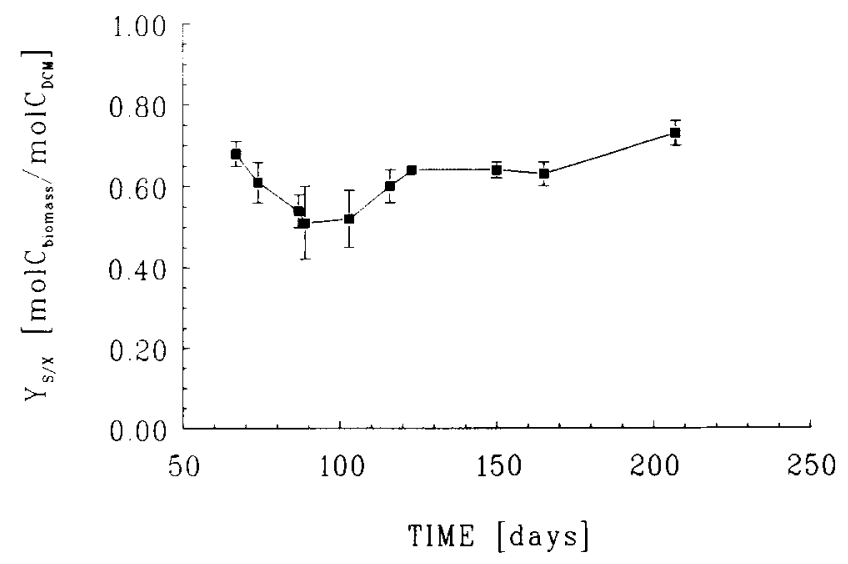

Figure 11. The yield of biomass on DCM by the primary microbial population in BTF vs. time; $Y_{s / x}$ derived from the performance curves as plotted in Fig. 7 and 8 and the corresponding $\mathrm{CO}_{2}$ production curves. (filled squares) increased from circa $0.2 \mathrm{~mol} \mathrm{CO}_{2} /\left(\mathrm{m}^{3} \cdot \mathrm{h}\right)$ at day 60 up to about $0.5 \mathrm{~mol} \mathrm{CO}_{2} /\left(\mathrm{m}^{3} \cdot \mathrm{h}\right)$ at day 200 . It is important to realize the rate of endogenous respiration is quite considerable as compared to the total $\mathrm{CO}_{2}$ production rate given in Figure 3 . In the long run it even becomes the dominating $\mathrm{CO}_{2}$-producing process.

In the interpretation of the results so far, it is implicitly assumed that the endogenous respiration is independent of the concentration of DCM in the system. As the secondary population has developed at standard conditions, i.e., in the presence of DCM, this assumption seems plausible. Nevertheless, the results given in Figure 10 only allow the calculation of the $R_{\mathrm{ER}}$ at $C_{g o}=0 \mathrm{~g} / \mathrm{m}^{3}$. To verify this assumption, the rate of endogenous respiration at standard conditions was calculated according to

$$
\mathrm{R}_{\mathrm{ER}-\mathrm{st}}=\mathrm{R}_{\mathrm{CO}_{2} \text {-st }}-\left(1-\mathrm{Y}_{\mathrm{s} / \mathrm{x}}\right) \cdot\left(-\mathrm{R}_{\mathrm{DCM}-\mathrm{st}}\right)
$$

in which $-R_{\mathrm{DCM}-\mathrm{st}}$ is the daily elimination capacity at standard conditions, $Y_{s / x}$ the actual yield coefficient and $R_{\mathrm{CO}_{2-s t}}$ the carbon dioxide production rate at standard conditions. The $-R_{\mathrm{DCM} \text {-st }}$ was determined from the $\mathrm{EC}_{\mathrm{GLC}}$ data given in Figure 2, whereas $Y_{s / x}$ and $R_{\mathrm{CO}_{2} \text {-st }}$ were determined from

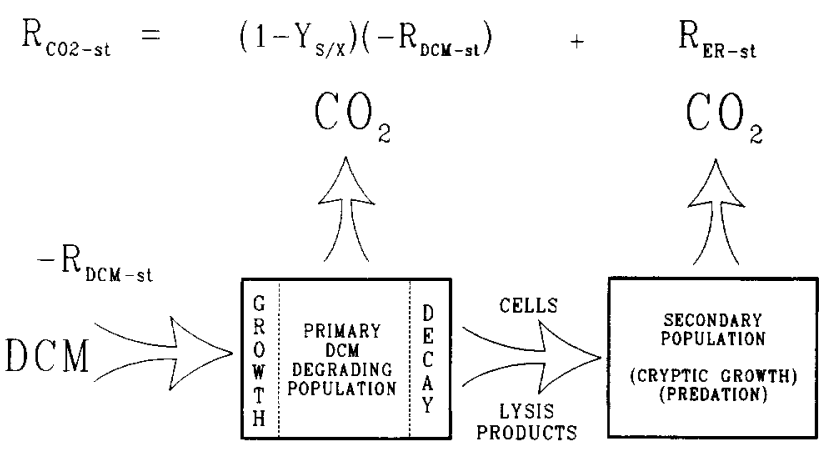

Figure 12. A schematic representation of the processes involved in the nearly complete conversion of DCM into carbon dioxide inside the biofilm. 


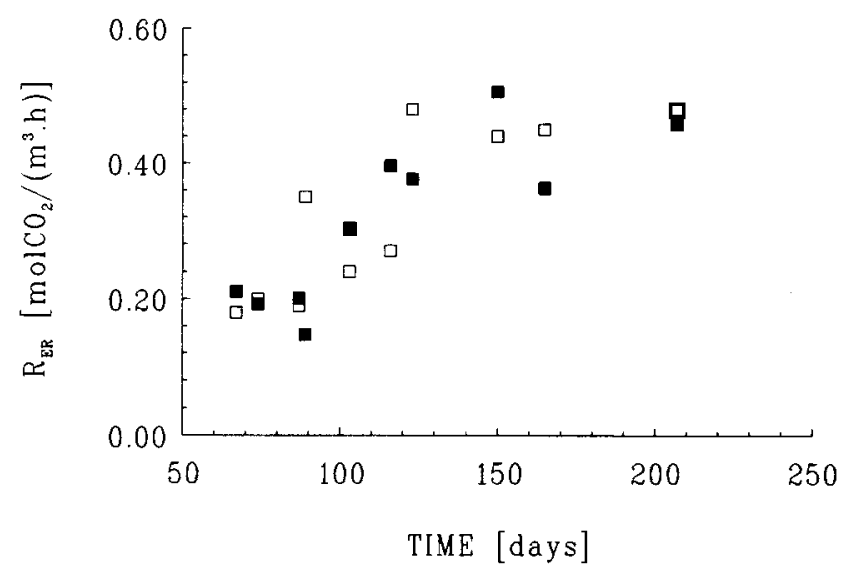

Figure 13. The rate of endogenous respiration $R_{\mathrm{ER}-\mathrm{st}}$ with ( $\square$ ) and $\mathrm{R}_{\mathrm{ER}}$ without DCM supplementation ( $(\mathbf{0})$ vs. time as calculated from the $-R_{\mathrm{DCM}}, R_{\mathrm{CO}_{2}-\mathrm{st}}$, and $Y_{s / x}$ (Table I).

the performance curves. All quantities are listed in Table I, whereas the resulting $R_{\mathrm{ER}-\mathrm{st}}$ is also plotted in Figure 13 (open squares). The good agreement between the value of $R_{\mathrm{ER}}$ and $R_{\mathrm{ER}-\mathrm{st}}$ indicates that the total rate of endogenous respiration is indeed not affected by the presence of DCM.

The active degradation and removal of biomass and/or biogenic material, being the major $\mathrm{CO}_{2}$-releasing process, thus appear to balance the microbial growth due to DCM elimination. It can hence be concluded that not only a constant steady-state elimination capacity but also a biological equilibrium can be achieved, due to the sequence of processes shown in Figure 12.

\section{CONCLUDING REMARKS}

In most biofilm models published in the literature, it is generally assumed without verification that no net biofilm growth occurs. The experimental results presented in this article show that such a biological equilibrium can actually develop in a trickling filter for the removal of DCM from waste gases. As a result of balance between bacterial growth and microbial biomass degradation, including respiration, cryptic growth, and predation, no net carbon accumulation in the form of biomass takes place in the long run. Moreover, the respiration processes involved in biomass degradation account for the major part of the $\mathrm{CO}_{2}$ production in the system $(60-70 \%)$. Consequently its existence is crucial for the development of a biological equilibrium.

It should be noted, however, that other factors may also play an important role in the stable operation of a biological trickling filter, e.g., the level of the organic load and the morphology of the biofilm. In case of DCM elimination, this morphology can be described as a flat aggregate of small flocs, which seems advantageous as compared with filamentous biofilm growth. The latter may result in an entanglement of biofilm filaments and support material by suspended biomass, which may lead to clogging phenomena.
Finally the results presented in this article suggest that the rate of elimination and hence the organic load will also influence the carbon balance. In order to achieve a biological steady state, a high substrate conversion rate necessitates the presence of a high rate of biomass degradation and hence a high content of secondary biomass in the biofilm.

The authors thank Kees van de Bosch, whose experimental investigations initiated this work. Also the contribution of Baukje Osinga and Adri van den Oever is greatly acknowledged.

\section{NOMENCLATURE}

\begin{tabular}{|c|c|}
\hline$C_{E}$ & exit concentration, $\mathrm{g} / \mathrm{m}^{3}$ \\
\hline$C_{l}$ & inlet concentration, $\mathrm{g} / \mathrm{m}^{3}$ \\
\hline$C_{g e}$ & outlet dichloromethane concentration in the gas phase, $\mathrm{g} / \mathrm{m}^{3}$ \\
\hline$C_{g o}$ & inlet dichloromethane concentration in the gas phase, $\mathrm{g} / \mathrm{m}^{3}$ \\
\hline EC & elimination capacity (based on $\mathrm{NaOH}$ consumption or gas- \\
\hline & liquid chromatography measurements $), \mathrm{mol} /\left(\mathrm{m}^{3} \cdot \mathrm{h}\right)$ \\
\hline $\mathrm{EC}_{\max }$ & maximum elimination capacity, $\mathrm{g} /\left(\mathrm{m}^{3} \cdot \mathrm{h}\right)$ \\
\hline$H$ & height of filterbed, m \\
\hline$m$ & gas-liquid distribution coefficient, $\mathrm{m}_{\mathrm{l}}^{3} / \mathrm{m}_{\mathrm{g}}^{3}$ \\
\hline OL & organic load to the filter, $\operatorname{mol} /\left(\mathrm{m}^{3} \cdot \mathrm{h}\right)$ \\
\hline$R_{\mathrm{CO}_{2}}$ & overall rate of $\mathrm{CO}_{2}$ production, $\mathrm{mol} /\left(\mathrm{m}^{3} \cdot \mathrm{h}\right)$ \\
\hline$R_{\mathrm{CO}_{2} \text {-st }}$ & $\mathrm{CO}_{2}$ production rate at standard conditions, $\mathrm{mol} /\left(\mathrm{m}^{3} \cdot \mathrm{h}\right)$ \\
\hline$R_{\mathrm{ER}}$ & $\begin{array}{l}\text { rate of endogenous respiration without dichloromethane } \\
\text { supplementation, } \mathrm{mol} /\left(\mathrm{m}^{3} \cdot \mathrm{h}\right)\end{array}$ \\
\hline$R_{\text {ER-cal }}$ & $\begin{array}{l}\text { rate of endogenous respiration at standard conditions, } \mathrm{mol} / \\
\left(\mathrm{m}^{3} \cdot \mathrm{h}\right)\end{array}$ \\
\hline$-R_{\mathrm{DCM}}$ & $\begin{array}{l}\text { molar elimination capacity of dichloromethane, mol/ } \\
\left(\mathrm{m}^{3} \cdot \mathrm{h}\right)\end{array}$ \\
\hline$-R_{\mathrm{DCM}-\mathrm{st}}$ & $\begin{array}{l}\text { molar elimination capacity at standard conditions, mol/ } \\
\left(\mathrm{m}^{3} \cdot \mathrm{h}\right)\end{array}$ \\
\hline$R_{\text {org }}$ & $\begin{array}{l}\text { removal rate of organic carbon via liquid drain, mol/ } \\
\left(\mathrm{m}^{3} \cdot \mathrm{h}\right)\end{array}$ \\
\hline$R_{\text {inorg }}$ & $\begin{array}{l}\text { removal rate of inorganic carbon via liquid drain, mol/ } \\
\left(\mathrm{m}^{3} \cdot \mathrm{h}\right)\end{array}$ \\
\hline 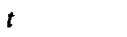 & time, days \\
\hline $\mathbf{v}_{l}$ & superficial liquid flow rate, $\mathrm{m} / \mathrm{h}$ \\
\hline$v_{8}$ & superficial gas flow rate, $\mathrm{m} / \mathrm{h}$ \\
\hline$Y_{\mathrm{CO}_{2}}$ & $\begin{array}{l}\text { overall yield coefficient on dichloromethane, } \mathrm{molC}_{\mathrm{CO}_{2}}{ }^{\prime} \\
\text { molC } C_{\mathrm{DCM}}\end{array}$ \\
\hline $\begin{array}{l}Y_{s / x} \\
V_{R}\end{array}$ & $\begin{array}{l}\text { true yield coefficient on substrate mol } C_{\text {biomass }} / \mathrm{mol} C_{\mathrm{DCM}} \\
\text { reactor volume: volume of filterbed } \mathrm{m}^{3}\end{array}$ \\
\hline
\end{tabular}

Subscripts

$t$ at time $t \quad 0 t \leqslant 0$

$1 t \rightarrow \infty$

\section{References}

1. Beck-Gasche, B. 1989. Untersuchungen zum Einsatz und Modellierung von Biowäschern. Fortschrittberichte der VDI-Zeitschriften, Reihe 15, nr. 68, VDI-Verlag, Düsseldorf.

2. Beer, D. de. 1990 . Microelectrode studies in biofilms and sediments. Thesis, University of Amsterdam, The Netherlands.

3. Bovendeur, J. 1989. Fixed-biofilm reactors applied to waste water treatment and aquacultural water recirculating systems. Thesis, Agricultural University of Wageningen, The Netherlands.

4. Bueb, M., Melin, Th. 1987. Biological and physico-chemical waste gas treatment processes; comparison of processes and cost; chances for new technologies. Proc. Int. Meeting Biol. Treatment of Ind. Waste Gases, DECHEMA, March 24-26, Heidelberg.

5. Diks, R. M. M. 1992. The removal of dichloromethane from waste 
gases in a biological trickling filter. Thesis, Eindhoven University of Technology, Eindhoven.

6. Diks, R. M. M., Ottengraf, S. P. P. 1991. Verification studies of a simplified model for the removal of dichloromethane from waste gases using a biological trickling filter; Part I. Bioproc. Eng. 6: 93-99.

7. Diks, R. M. M., Ottengraf, S. P. P. 1991. Verification studies of a simplified model for the removal of dichloromethane from waste gases using a biological trickling filter; Part II. Bioproc. Eng. 6: 131-140.

8. Gälli, R., Leisinger, Th. 1985. Specialized strains for the removal of dichloromethane from industrial waste. Cons. Rec. 8(1/2): 91-100.

9. Gossen, C. A. (1991). Abgasreinigung mit fixierten Bakterien im Rieselbett. Thesis, Munich University of Technology, Munich.

10. Hartmans, S., Tramper, J. 1991. Dichloromethane removal from waste gases with a trickle-bed bioreactor. Bioproc. Eng. 6: 83-92.

11. Janssen, D. B., Kuijk, L., Witholt, B. 1987. Feasibility of specialized microbial cultures for the removal of xenobiotic compounds.
Proc. Int. Meeting on Biol. Treatment of Ind. Waste Gases, DECHEMA, March 24-26, Heidelberg.

12. Kohler, H. 1982. Behandlung geruchintensiver Abluft in Wäschern unter Verwendung einer Belebtschlammsuspension. Fortschrittberichte der VDI-Zeitschriften, Reihe 15, nr. 22, VDI-Verlag, Düsseldorf.

13. Ottengraf, S. P. P., Meesters, J. J. P., Oever, A. H. C., van den Rozema, H. R. 1986. Biological elimination of volatile xenobiotic compounds in biofilters. Bioproc Eng. 1: 61-69.

14. Perry, R., Green, D. 1987. Chemical engineering handbook, 6th ed., McGraw-Hill, New York.

15. Rittman, B. E. 1980. Model of steady-state biofilm kinetics. Biotechnol. Bioeng. 22: 2343-2357.

16. Roszak, D. B., Colwell, R. R. 1987. Survival strategies of bacteria in the natural environment. Microbiol. Rev. 51: 365-379.

17. Schirz, S. 1975. Abluftreinigungsverfahren in der Intensivtierhaltung. KTBL-Schrift 200, Landwirtschaftsverlag, Münster.

18. Wanner, O., Guijer, W. 1986. A multi-species biofilm model. Biotechnol. Bioeng. 28: 314-328. 